www.ijpsonline.com

\title{
Design and Synthesis of Biogenic Silver Nanoparticles from Andragraphis paniculata as Potential Anticancer Agents
}

\author{
P. SELVAM* AND A. WADWANI ${ }^{1}$
}

Sir C. V. Raman- K. S. Krishnan International Research Centre, Kalasalingam University, Krishnankoil-626 126, ${ }^{1}$ Department of Pharmaceutical Biotechnology, Jagadguru Sri Shivarathreeshwara University (JSS) College of Pharmacy, Ooty-643 001, India

\author{
Selvam and Wadhwani: Synthesis and Anticancer Screening of Andrographis paniculata Silver \\ Nanoparticles
}

\begin{abstract}
Present investigation aimed to biosynthesize silver nanoparticles using methanol leaf extract of Andrographis paniculata and screen those for anticancer activity. The synthesized nanoparticles were confirmed through colour transformation and surface plasmon resonance. Size and morphology of the nanoparticles were characterized using scanning electron microscope and energy-dispersive X-ray. Stability of silver nanoparticles was detected using Fourier-transform infrared spectroscopy and powder X-ray diffraction. Reddish-brown appearance and ultraviolet absorption at $468 \mathrm{~nm}$ confirmed the presence of silver nanoparticles. Scanning electron microscopy indicated that the silver nanoparticles were spherical with a size ranging from 18$70 \mathrm{~nm}$. Fourier-transform infrared spectra of silver nanoparticles showed peaks corresponding to the functional groups $\mathrm{C}=\mathrm{O},-\mathrm{C}=\mathrm{C}, \mathrm{C}-\mathrm{H}$, which indicated that the synthesized silver nanoparticles were stable. Anticancer activity of Andrographis paniculata methanol leaf extract silver nanoparticles was tested against neuroblastoma cells and normal Vero cells using the 3-[4,5-dimethylthiazol-2-yl]-2,5 diphenyl tetrazolium bromide assay. Andrographis paniculata methanol leaf extract and its nanoparticles showed anticancer activity against neuroblastoma cells with $\mathrm{IC}_{50}$ value of 32 and $60 \mu \mathrm{g} / \mathrm{ml}$, respectively. The nanoparticles and leaf extract were not cytotoxic to Vero cell lines $\left(\mathrm{CC}_{50}\right.$ value of 329.29 and $\left.368 \mu \mathrm{g} / \mathrm{ml}\right)$. The silver nanoparticles of methanol extract of Andrographis paniculata leaves could be a potential anticancer agent against neuroblastoma cells.
\end{abstract}

Key words: Andrographis paniculata, neuroblastoma cells (SH SY5Yc), Vero cells, silver nanoparticles

Andrographis paniculata (Acanthaceae) is a versatile medicinal plant being a very good source for a variety bioactive molecules such as andrographin and andrographolide, which possessed a board-spectrum of biological actions ${ }^{[1]}$. Neuroblastoma (NB) cell lines are transformed into, neural crest derived cells, capable of uncontrolled proliferation in vitro ${ }^{[2]}$. NB cell lines retain the ability of differentiation into neuronal cell types on treatment with various chemical agents ${ }^{[3,4]}$. This ability of NB cells to proliferate as well as to differentiate makes it an excellent in vitro system for various studies.

Review of literature revealed that the A. paniculata silver nanoparticles (APAgNPs) were documented for anticancer ${ }^{[5]}$, hepatoprotective ${ }^{[6]}$ and antibacterial activity $^{[7-9]}$. Based on the above medicinal values of APAgNPs, current work was planned to synthesize and characterize the AgNPs from the methanol leaf

*Address for correspondence

E-mail: selvaamin@gmail.com

173

Indian Journal of Pharmaceutical Sciences extract of $A$. paniculata and to evaluate their anticancer potential against NB cells (SH SY5Yc) and Vero cells.

Fresh leaves of $A$. paniculata were collected from Watrap area, Virudhu Nagar district, Tamilnadu, dried under shade and powdered. One hundred grams of A. paniculata leaves powder was packed in a Soxhlet apparatus and extracted using hot continuous extraction process with methanol at $100^{\circ}$ for $48 \mathrm{~h}$ to achieve complete extraction. Solvent was recovered from the leaf extract by distillation to concentrate the extract. Extract was dried under vacuum and stored under $5^{\circ}$ until further use.

This is an open access article distributed under the terms of the Creative Commons Attribution-NonCommercial-ShareAlike 3.0 License, which allows others to remix, tweak, and build upon the work non-commercially, as long as the author is credited and the new creations are licensed under the identical terms

Accepted 07 December 2018

Revised 01 May 2018

Received 23 August 2017

Indian J Pharm Sci 2019;81(1):173-176 
Silver nitrate $\left(\mathrm{AgNO}_{3}\right)$ was obtained from HiMedia (Mumbai, India). Aqueous solution of $1 \mathrm{mM} \mathrm{AgNO}_{3}$ was used for the synthesis of AgNPs. For the preparation of AgNPs, $5 \mathrm{ml}$ of $A$. paniculata leaf methanol extract (100 mg dried methanol extract was dissolved in $5 \mathrm{ml}$ of distilled water to make a $2 \% \mathrm{~W} / \mathrm{V}$ solution) was mixed with $95 \mathrm{ml}$ of $1 \mathrm{mM} \mathrm{AgNO}_{3}$ solution in a conical flask. Flask was stirred in a magnetic stirrer for $3 \mathrm{~h}$ at $200 \mathrm{rpm}$. The AgNPs obtained were analysed in a $\mathrm{UV} /$ Vis double beam spectrophotometer in the range of $350-800 \mathrm{~nm}$.

UV/Vis spectrum of the AgNPs obtained from A. paniculata was used for calculation of plasmon resonance band in a Shimadzu double beam UV/Vis spectrophotometer. The scanning electron microscopy (SEM) study was carried out on a Carl Zeiss EVO-18 electron microscope. For SEM imaging to visualize the morphological size and shape of the APAgNPs, a sample of the nanoparticles solution was placed on a carbon strip attached to a SEM brass, extra solution was wiped off using a blotting paper and then allowed to dry under a mercury lamp for $5 \mathrm{~min}$. The Fouriertransform infrared spectra were analysed using IR Tracer-100 Shimadzu, Fourier-transform infrared spectroscopy (FTIR) and using the spectral range 4000$400 \mathrm{~cm}^{-1}$. A small amount APAgNPs is placed in ATR diamond disc (zinc selenide) for FTIR measurement. The crystalline and the lattice characteristics of the synthesized APAgNPs were measured by powder X-ray diffraction (XRD) analysis. The XRD measurement was carried out on thoroughly dried thin films of the purified APAgNPs, which was spread on a glass slab on a D8 Advance ECO XRD Systems with SSD160 1D Detector-Bruker XRD 6000 instrument operated at a voltage of $20 \mathrm{keV}$ and a current of $30 \mathrm{~mA}$ with $\mathrm{CuK} \alpha 1$ radiation $(\lambda=0.1542)$ in a $\theta-2$ theta (degree) configuration.

Methanol extract and the AgNPs there from were studied for anticancer activity against SH SY5Yc cells and for cytotoxicity against normal Vero cells using the 3-[4,5-dimethylthiazol-2-yl]-2,5 diphenyl tetrazolium bromide (MTT) assay ${ }^{[10]}$. The parameters such as inhibitory concentration $\left(\mathrm{IC}_{50}\right)$ and cytotoxic concentrations $\left(\mathrm{CC}_{50}\right)$ were measured for the analysis of anticancer and cytotoxicity potential of APAgNPs.

In this investigation, AgNPs were synthesized by the addition of the methanol extract of $A$. paniculata leaves to $\mathrm{AgNO}_{3}$ solution and stirring the mixture on a magnetic stirrer till colour of the reaction medium changed from colourless to reddish-brown (fig. 1). The biosynthesis of AgNPs was initially confirmed using surface plasmon resonance phenomenon and UV/Vis spectra. The AgNPs obtained from A. paniculata leaf extract gave a plasmon resonance band at $468 \mathrm{~nm}$ (fig. 1). The peak position did not change with time indicating the stability of the AgNPs formed. The FT-IR experiments were carried out to identify the compounds responsible for the bioreduction of Ag ions and capping of the bio-reduced AgNPs (fig. 2). FT-IR spectrum of the AgNPs of leaf extract showed peaks at 3410,2881 and 2821, 1764, 1382, 1083 and $82 \mathrm{~cm}^{-1}$

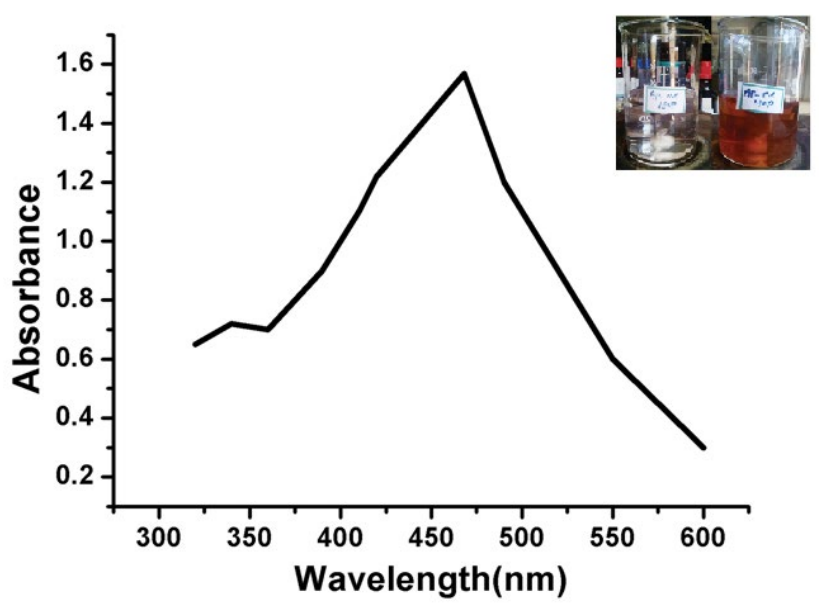

Fig. 1: UV/Vis spectrum of biosynthesized AP-Me AgNPs Colour of the reaction medium transferred from colorless to reddish-brown and UV/Vis spectrum of APAgNPs gave a plasmon resonance band at $468 \mathrm{~nm}$

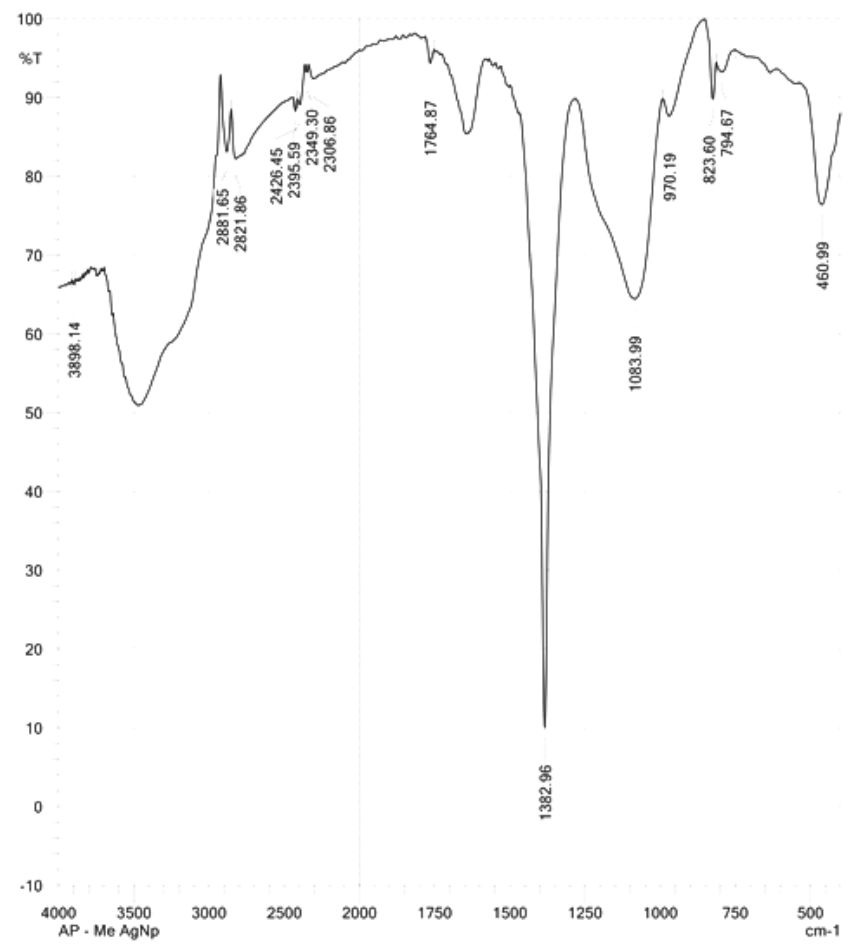

Fig. 2: FTIR spectrum of the APAgNPs 
in the region of $4000-500 \mathrm{~cm}^{-1}$. The absorption peak at $1764 \mathrm{~cm}^{-1}$ represented carbonyl group $(\mathrm{C}=\mathrm{O})$, the peak at $3390 \mathrm{~cm}^{-1}$ represented hydroxyl group (-OH) and peaks from 2881 and $2821 \mathrm{~cm}^{-1}$ indicated the alkyl stretching. Peak at $1083 \mathrm{~cm}^{-1}$ for C-O-C and $821 \mathrm{~cm}^{-1}$ for Ar-H. To investigate the crystalline nature of the biosynthesized AgNPs, XRD analysis was performed. Fig. 3 revealed two peaks at degree $2 \theta 35.1^{\circ}, 36.2^{\circ}$, corresponding to two diffractions from (220), (122) planes of silver (as correlated to JCPDS: file no. 4-783). The nanoparticles are spherical in shape and crystalline in nature ${ }^{[11]}$. SEM analysis was used to study the morphology of APAgNPs and fig. 4 depicts the size and shape of nanoparticles. AgNPs were spherical in shape and their size ranged from 18-70 nm under SEM observations.

Anticancer activity of these APAgNPs was tested against SH SY5Yc cells and cytotoxicity was investigated in normal Vero cells $(n=3)$ using the MTT assay. APAgNPs and the methanol leaf extract showed anticancer activity against SH SY5Yc cells with $\mathrm{IC}_{50}$ value of 32 and $60 \mu \mathrm{g} / \mathrm{ml}$, respectively (fig. 5A and B). The nanoparticles and leaf extract did not show cytotoxicity against Vero cell lines at these concentrations and the $\mathrm{CC}_{50}$ values were found to be 329.29 and $368 \mu \mathrm{g} / \mathrm{ml}$, respectively (fig. 6A and B). From previous reports, the AgNPs prepared from the ethanol extract of $A$. paniculata exhibited significant antibacterial activity ${ }^{[12,13]}$. Gold nanoparticles biosynthesized from $A$. paniculata leaf ethanol extract had potent cytotoxicity against HeLa cells ${ }^{[14]}$.

In conclusion, complete extraction was achieved using hot continuous process resulting in the maximum bioactive molecule content in the extract. Biosynthesize of AgNPs using methanol extract of

A.

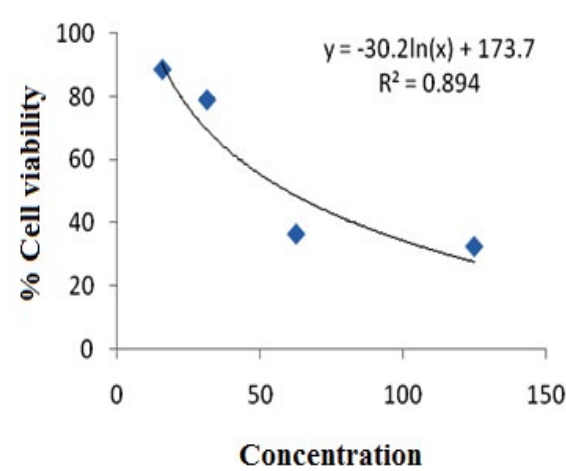

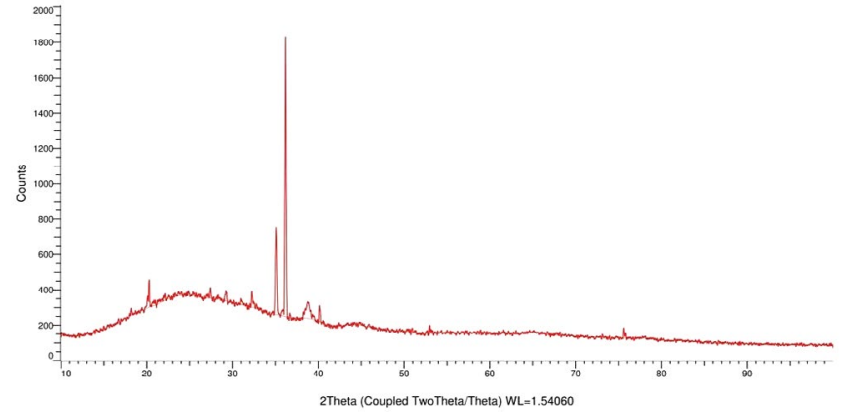

Fig. 3: XRD pattern of the APAgNPs

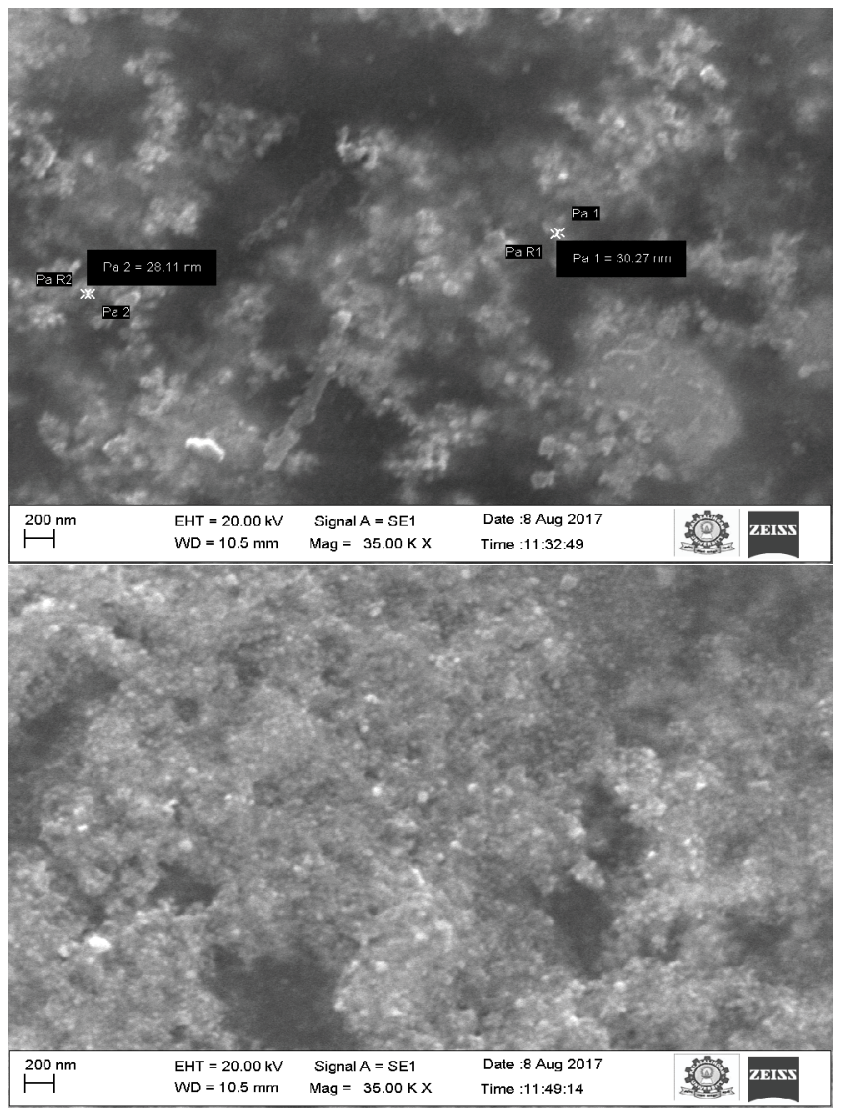

Fig. 4: SEM micrograph of the APAgNPs

Based on the above observations, AgNPs were found to be spherical in shape with a size range of $18-70 \mathrm{~nm}$

B.

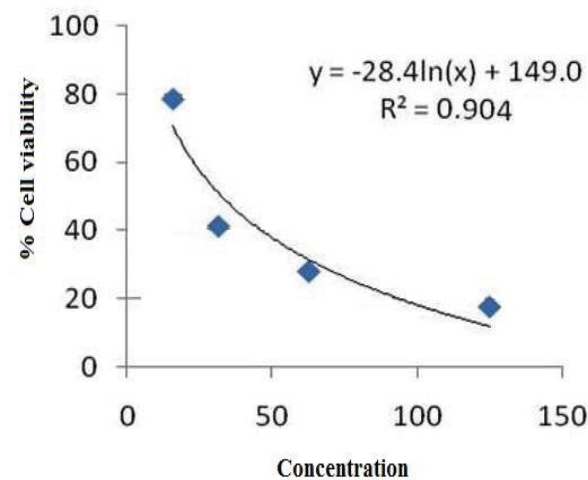

Fig. 5: Cytotoxicity of APAgNPs and the methanol extract on SH SY5Yc cells Cytotoxicity of (A) APAgNPs and (B) Andrographis paniculata leaf methanol extract in neuroblastoma cells (SH SY5Yc) cells. - Percent viability; - $\log \%$ viability 
A.

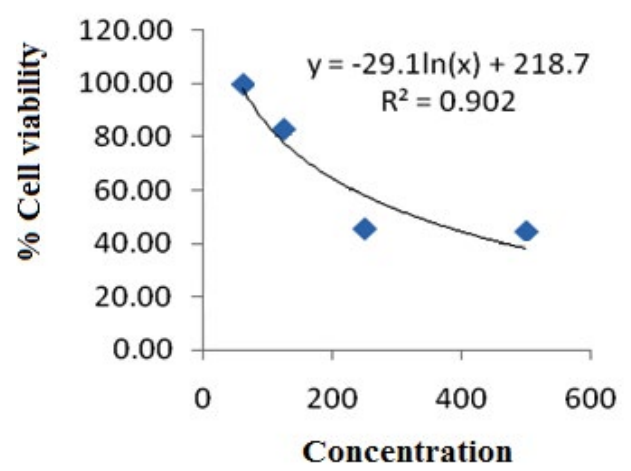

B.

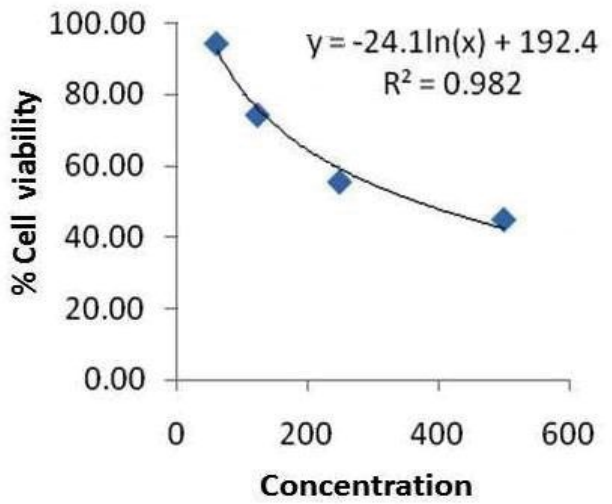

Fig. 6: Cytotoxicity APAgNPs and the methanol extract on Vero cells Cytotoxicity of (A) APAgNPs and (B) Andrographis paniculata leaf methanol extract in Vero cells, $\diamond$ Percent viability; — log (\% viability)

leaves of $A$. paniculata would help in preparing potent cytotoxic agents to destroy tumor cells. To the best of our knowledge, this is the first report in the literature demonstrating the anticancer activity of APAgNPs against NB cells.

\section{Conflicts of interest:}

The authors declare that there is no conflict of interests in this paper.

\section{Financial support and sponsorship:}

Nil.

\section{REFERENCES}

1. Hossain MS, Urbi Z, Sule A, Hafizur Rahman KM. Andrographis paniculata (Burm. f.) Wall. ex Nees: A review of ethnobotany, phytochemistry and pharmacology. ScientificWorldJournal 2014;2014:274905.

2. Biedler JL, Helson L, Spengler BA. Morphology and growth, tumorigenicity and cytogenetics of human neuroblastoma cells in continuous culture. Cancer Res 1973;33(11):2643-52.

3. Biedler JL, Roffler-Tarlov S, Schachner M, Freedman LS. Multiple neurotransmitter synthesis by human neuroblastoma cell lines and clones. Cancer Res 1978;38:3751-7.

4. La Quaglia MP, Manchester KM. A comparative analysis of neuroblastic and substrate-adherent human neuroblastoma cell lines. J Pediatr Surg 1996;31(2):315-18.

5. Prasannaraj G, Venkatachalam P. Hepatoprotective effect of engineered silver nanoparticles coated bioactive compounds against diethylnitrosamine induced hepatocarcinogenesis in experimental mice. J Photochem Photobiol B 2017;167:309-20.

6. Suriyakalaa U, Antony JJ, Suganya S, Siva D, Sukirtha
$\mathrm{R}$, Kamalakkannan $\mathrm{S}$, et al. Hepatocurative activity of biosynthesized silver nanoparticles fabricated using Andrographis paniculata. Colloids Surf B Biointerfaces 2013;102:189-94.

7. Azmath P, Baker S, Rakshith D, Satish S. Mycosynthesis of silver nanoparticles bearing antibacterial activity. Saudi Pharm J 2016;24:140-6.

8. Kotakadi VS, Gaddam SA, Subba Rao Y, Prasad TN, Varada Reddy A, Sai Gopal DV. Biofabrication of silver nanoparticles using Andrographis paniculata. Eur J Med Chem 2014;73:135-40.

9. Mandal D, Dash SK, Das B, Chattopadhyay S, Ghosh T, Das $\mathrm{D}$, et al. Bio-fabricated silver nanoparticles preferentially targets Gram-positive depending on cell surface charge. Biomed Pharmacother 2016;83:548-58.

10. Skehan P, Storeng R, Scudiero D, Monks A, McMahon J, Vistica D, et al. New colorimetric cytotoxic assay for anticancer drug screening. J Natl Cancer Inst 1990;82(13):1107-12.

11. Supratim B, Antoine F, Mulaba-Bafubiandi. Optimization of process variables for the biosynthesis of silver nanoparticles by Aspergillus wentii using statistical experimental design. Adv Nat Sci Nanosci Nanotechnol 2016;7:1-10.

12. Ravi D, Sathish S, Parthasarathy R, Priyadharshini M, Revathy $M$. Synthesis and characterization of silver nanoparticles from Andrographis paniculata (linn.) and it's cytotoxicity against sheep's bone marrow cells. Int J Biol Pharm Res 2013;4:1222-8.

13. Ananda Chitra M, Ramesh S. Antibacterial activity of silver nanoparticles synthesized using Phyllanthus amarus aqueous and Andrographis paniculata ethanolic extracts. Indian J Anim Sci Res 2015;44:12-9.

14. Punuri JB, Sibyala S, Pragya S, Ranjan T, Utpal B. Gold nanoparticles: sonocatalytic synthesis using ethanolic extract of Andrographis paniculata and functionalization with polycaprolactone-gelatin composites. Front Mat Sci 2012;6:236-49. 